\title{
The influence of habitat quality on the foraging strategies of the entomopathogenic nematodes Steinernema carpocapsae and Heterorhabditis megidis
}

\author{
L. M. KRUITBOS ${ }^{1}, \mathrm{~S}$. HERITAGE ${ }^{2}$, S. HAPCA ${ }^{3}$ and M. J. WILSON ${ }^{1 *}$ \\ ${ }^{1}$ Institute of Biological and Environmental Sciences, University of Aberdeen, Cruickshank Building, Aberdeen, \\ AB24 $3 U U, U K$ \\ ${ }^{2}$ Forestry Commission, Northern Research Station, Roslin. Midlothian EH25 9SY, UK \\ ${ }^{3}$ Simbios Centre, University of Abertay Dundee, 40 Bell Street, Dundee DD1 1HG, UK
}

(Received 29 April 2009; revised 3 fune, 15 Fune, 21 fune and 27 Fuly 2009; accepted 28 fuly 2009; first published online 16 October 2009)

SUMMARY

Entomopathogenic nematodes (EPN) are soil-transmitted parasites and their foraging strategies are believed to range from 'ambush' to 'cruise' foragers. However, research on their behaviour has not considered the natural habitat of these nematodes. We hypothesized that EPN behaviour would be influenced by soil habitat quality and tested this hypothesis using 2 EPN species Steinernema carpocapsae (an 'ambusher') and Heterorhabditis megidis (a 'cruiser') in 2 contrasting habitats, sand and peat. As predicted from previous studies, in sand most $S$. carpocapsae remained at the point of application and showed no taxis towards hosts, but in peat $S$. carpocapsae dispersed much more and showed a highly significant taxis towards hosts. H. megidis dispersed well in both media, but only showed taxis towards hosts in sand. In outdoor mesocosms in which both species were applied, $S$. carpocapsae outcompeted H. megidis in terms of host finding in peat, whereas the opposite was true in sand. Our data suggest that these 2 EPN may be habitat specialists and highlight the difficulties of studying soil-transmitted parasites in non-soil media.

Key words: Heterorhabditis megidis, Steinernema carpocapsae, behaviour, foraging, habitat, body waving.

\section{INTRODUCTION}

Many parasites (e.g. Strongyloides stercoralis, Ancylostoma duodenale and numerous parasites of invertebrates) have soil-transmitted infective stage larvae that need to find hosts, yet we know little about their host finding behaviour. Soil is the most complex biomaterial on earth (Young and Crawford, 2004) and its opaque nature makes studying behaviour of soil animals challenging.

Entomopathogenic nematodes (EPN) are soiltransmitted parasites that are lethal to a wide range of host insects (Kaya and Gaugler, 1993) and are mass-produced and sold as biological insecticides throughout the world (Kaya et al. 2006). These parasites form non-feeding infective juveniles which carry cells of entomopathogenic bacteria within their intestines. When these juveniles penetrate an insect, they release the bacteria, thus killing the host insect. The nematodes then feed and reproduce on the decaying insect and bacteria, forming infective juveniles when the resources are depleted (Kaya and Gaugler, 1993; Emelianoff et al. 2008).

* Corresponding author: Institute of Biological and Environmental Sciences, University of Aberdeen, Cruickshank Building, Aberdeen AB24 3UU, UK. Tel: +44 1224 272845. Fax: +44(0) 1224 272945. E-mail: m.j.wilson@abdn.ac.uk
The behaviour of EPN has been studied intensively since the early 1990s and different EPN species behave very differently in terms of dispersal, hostfinding, scavenging and body waving (standing on their tails) (Lewis, 2002; Ramos-Rodríguez et al. 2007 ; San-Blas and Gowen, 2008). These differences have been explained using the theoretical framework of optimal foraging (Pyke et al. 1977), even though it has been acknowledged that this may not be applicable to this group of nematodes (Lewis, 2002). EPN foraging strategies are believed to range on a continuum from 'ambush' (sit-and-wait) to 'cruise' foragers (widely foraging) (Lewis et al. 1992; Grewal et al. 1994), and the choice of EPN species for use in biological control is based largely on foraging strategy. Ambush foragers are used to control surface active pests whereas 'cruise' foragers are used to control pests that live deep in the soil profile.

Certain EPN species are known to show habitat preferences (Hominick, 2002; Spiridonov et al. 2004; Torr et al. 2007 b) but authors describing such preferences usually attribute them to availability of susceptible hosts rather than to habitat quality per se. However, this hypothesis has never been tested, and conflicts with evidence that most EPN are host generalists (Klein, 1990; Kaya and Gaugler, 1993).

We hypothesized that the very different behaviours of EPN and their distributions may in part 
reflect habitat specialization. To test this hypothesis, we investigated host finding, behaviour and competitive ability of $2 \mathrm{EPN}$ species (Steinernema carpocapsae (Weiser), an 'ambusher' and Heterorhabditis megidis Poinar, Jackson \& Klein, a 'cruiser' in 2 contrasting soil habitats: sand and peat. These two soil types are typical of those used for commercial forestry in boreal regions, and where EPN are used to control the large pine weevil Hylobius abietis (Dillon et al. 2006, 2008; Torr et al. 2007 a).

MATERIALS AND METHODS

\section{Nematodes}

Infective juveniles (IJs) of Steinernema carpocapsae, and Heterorhabditis megidis (obtained from Becker Underwood, Littlehampton, UK) were reared in larvae of the greater wax moth Galleria mellonella (Lepidoptera: Pyralidae) obtained from Wiggly Wigglers (Blakemere, UK) according to Kaya and Stock (1997). The suspension of IJs were maintained in plastic tissue-culture flasks and stored at $4{ }^{\circ} \mathrm{C}$ until testing for no more than 4 weeks.

\section{Host finding assays}

Host finding was investigated using bioassay tubes $(28 \mathrm{~cm} \times 3.6 \mathrm{~cm}$ diameter $)$ which comprised 7 individual cylinders of $4 \mathrm{~cm} \times 3.6 \mathrm{~cm}$ diameter taped together. Cylinders were loosely packed with either sand (building sand) with very low organic matter $(0.53 \% \mathrm{w} / \mathrm{w})$ or peat $(100 \%$ garden peat $)$ with very high organic matter content $(94 \% \mathrm{w} / \mathrm{w})$, both obtained from B\&Q (Easteigh, UK). Nematodes (15000 in $1 \mathrm{ml}$ of water) were inoculated through a small hole (approx. $0.5 \mathrm{~mm}$ diameter) into the middle of the central section. Three $G$. mellonella hosts were placed at one end of each cylinder. Bioassay tubes were kept horizontally in the dark at room temperature for approximately $72 \mathrm{~h}$. After this time cylinders were dismantled and nematodes in each section were extracted using Baermann funnels for $24 \mathrm{~h}$ prior to counting (Kaya and Stock, 1997). Eight replicate tubes were used for each treatment, and the experiment was repeated. All experiments also included 8 replicate control tubes that did not contain host insects for each habitat and species.

\section{Body-waving behaviour}

Petri dishes $(90 \mathrm{~mm})$ filled with agar (1\% Bacteriological Agar, Oxoid Ltd, Basingstoke) were sprinkled with either $0.14 \mathrm{~g}$ sand or $0.02 \mathrm{~g}$ peat (equating to approximately $0.085 \mathrm{~cm}^{3}$ of medium). IJs (500) of either S. carpocapsae or H. megidis, in $20 \mu \mathrm{l}$ of water, were added to each plate. The total numbers of body-waving nematodes per plate were recorded after $24 \mathrm{~h}$. Each plate was counted 3 times and the mean taken. A nematode was recorded to be body waving if the majority of the nematode's body was raised from the substrate in either a straight posture or 'waving' motion (Campbell and Gaugler, 1993). There were 4 replicate Petri dishes per treatment, and the experiment was repeated.

\section{Interspecific competition for hosts}

Mesocosms consisting of PVC drainage pipe $(48 \mathrm{~cm}$ long; $10 \mathrm{~cm}$ inner diameter), sealed at the bottom with a plant-pot saucer, were filled with either sand or peat to a height of $45 \mathrm{~cm}$. Plastic mesh bags (aperture $1 \mathrm{~mm} \times 1 \mathrm{~mm}$ ) containing 10 Tenebrio molitor (Coleoptera: Tenebrionidae) larvae were buried at depths of $5 \mathrm{~cm}, 15 \mathrm{~cm}, 25 \mathrm{~cm}, 35 \mathrm{~cm}$ and $45 \mathrm{~cm}$. In all mesocosms a mixed inoculation of both $H$. megidis and $S$. carpocapsae (21000 of each species) was applied in $20 \mathrm{ml}$ of water using a pipette to the surface. After 1 week, the mesocosms were dismantled and the numbers of $T$. molitor infected with either $S$. carpocapsae or H. megidis were recorded. Infection by entomopathogenic nematodes was characterized by body shape and maintenance of cuticular integrity and by brick-red colouration in the case of $H$. megidis and a lightening of colour in the case of $S$. carpocapsae. We saw no evidence of mixed infections.

The experiment was repeated and used 3 replicate mesocosms per habitat in the first experiment followed by 4 replicates in the second. The experiment was conducted in the University of Aberdeen Cruickshank Botanic Gardens, UK. Temperatures within mesocosms were recorded regularly and varied between $16{ }^{\circ} \mathrm{C}$ and $22^{\circ} \mathrm{C}$ during the experiments.

\section{Statistical analyses}

For host finding assays, percentages of recovered nematodes that migrated towards hosts or away from hosts were compared using the Student's $t$-test. Analysis of fitted values $v s$ residuals indicated that no data transformation was necessary. Numbers of body-waving nematodes per plate were analysed using a two-way Analysis of Variance (ANOVA) following $\log$ transformation $\ln (\mathrm{x}+1)$.

For the interspecific competition experiment, generalized estimation equation models for normal data (GEEs) were used to compare the proportions of $T$. molitor infected by $S$. carpocapsae and $H$ megidis, within the 2 habitats (peat and sand). To satisfy model assumptions, data were transformed using the angular transformation prior to analysis. To determine how the proportion of infected $T$. molitor varied with habitat, we first applied factorial GEEs with the within-subject factor species ( $S$. carpocasae and $H$. megidis) and the between-subjects factor habitat (peat and sand). Data were expressed as 


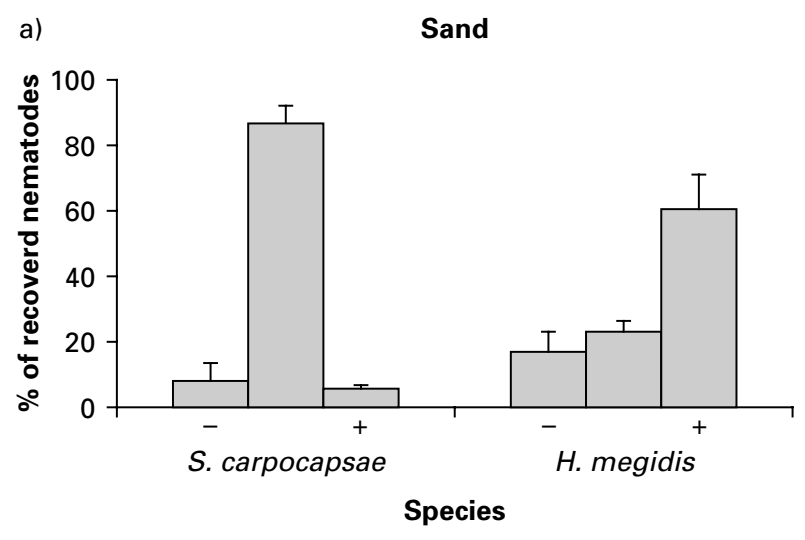

b)

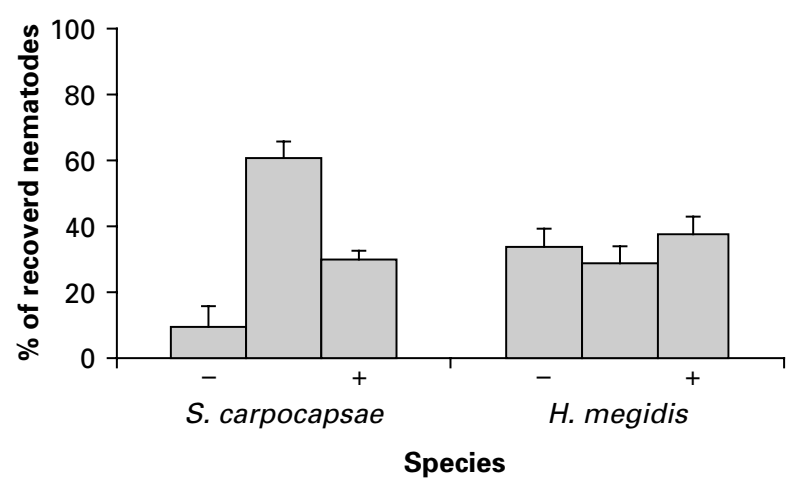

Fig. 1. Mean percentage \pm s.E.M. of recovered Steinernema carpocapsae and Heterorhabditis megidis migrating through sand or peat towards hosts Galleria mellonella $(+)$ or away from hosts $(-)$ after $72 \mathrm{~h}$.

proportions of $T$. molitor infected by $S$. carpocapsae and $H$. megidis from the total recovered per mesocosm. Due to the strong interaction effects between the factors, the analysis was then repeated for each species separately using one-way ANOVA to determine the main effects of habitat. Next, to determine how the infection rate varied with depth, new proportions were calculated from the total recovered from each depth, and factorial GEEs comprising 2 within-subject factors (species and depth) and 1 between-subject factor (habitat) were applied. Due to strong interaction effects among the 3 factors, the GEEs analysis was then repeated for each habitat separately and the interaction effect between species and depth was analysed. The analyses were done using MINITAB 15 (Minitab Inc, USA) and SPSS v. 16. (SPSS Inc, Chicago) for the interspecific competition experiment.

\section{RESULTS}

\section{Host finding assays}

In sand, $H$. megidis dispersed throughout the bioassay tubes and showed a strong significant taxis towards hosts $(t=5 \cdot 03, P<0 \cdot 001)$ (Fig. 1a) whereas most $S$. carpocapsae remained at the point of

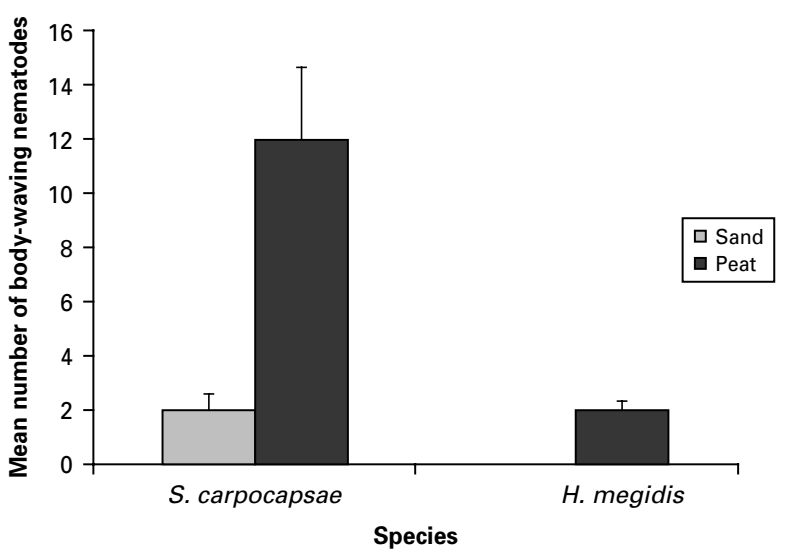

Fig. 2. Mean \pm s.E.M. numbers per plate of Steinernema carpocapsae and Heterorhabditis megidis observed body waving on agar plates sprinkled with sand or peat.

application and showed no taxis $(t=-0 \cdot 36, P=0 \cdot 72)$ (Fig. 1a). In peat, the percentage of $S$. carpocapsae that had dispersed from the point of application was significantly greater than in sand $(t=3.72$, $P=0 \cdot 003)$. In addition, $S$. carpocapsae showed significant taxis towards hosts $(t=4 \cdot 27, P \leqslant 0 \cdot 001$; Fig. 1b). In contrast, H. megidis showed no taxis towards hosts in peat although levels of dispersal were similar in both habitats.

In control experiments using tubes containing no insects, nematodes dispersed throughout the tubes to similar levels to those shown in Fig. 1, but showed no preference $(P>0 \cdot 05)$ for either test zone.

\section{Body waving behaviour}

Nematode species and media had a significant effect on body-waving behaviour $\left(F_{1,28}=71 \cdot 79, P<0 \cdot 001\right.$; $F_{1,28}=73.74, \quad P<0.001$, respectively). However, the interaction between factors was not significant $\left(F_{1,28}=0 \cdot 15, P=0 \cdot 701\right)$. On sand, only $S$. carpocapsae was seen body waving, but significantly more $S$. carpocapsae were found body waving on peat (Fig. 2). H. megidis (not previously thought to show this behaviour) body waved in low numbers on peat but not on sand (Figs 2 and 3 and Supplementary video - Online version only).

\section{Interspecific competition for hosts}

The interaction between habitat and species was highly significant (Wald $\chi^{2}=79.99$, D.F. $=1, P<$ $0 \cdot 001$ ), showing that $S$. carpocapsae outcompeted $H$. megidis in peat, whereas in sand, H. megidis outcompeted $S$. carpocapsae (Fig. 4A). When analysed separately, the proportions of $T$. molitor infected by $S$. carpocapsae and $H$. megidis varied significantly with habitat $(\mathrm{F}=29 \cdot 90$, D.F. $=1,12, P<0.001$ for $S$. carpocapsae and $\mathrm{F}=46 \cdot 28$, D.F. $=1,12, P<0 \cdot 001$ for $H$. megidis). When the proportions were calculated for each depth, strong interaction effects among 


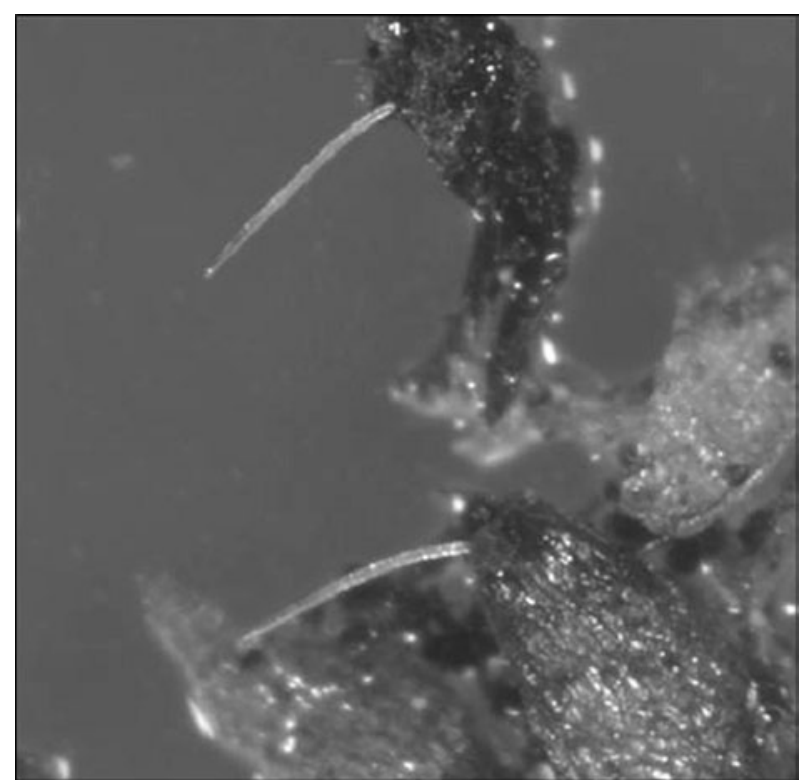

Fig. 3. Heterorhabditis megidis infective juveniles body waving on peat.

habitat, species and depth were also obtained (Wald $\chi^{2}=65 \cdot 31$, D.F. $\left.=4, P<0 \cdot 001\right)$. When analysed separately strong interaction effects between species and depth were obtained in both habitats with the proportion of $T$. molitor infected by $S$. carpocapsae decreasing with depth and proportion of those infected by $H$. megidis increasing with depth (Fig. 4B). The interaction effect between species and depth was also significant (Wald $\chi^{2}=224 \cdot 134$, D.F. $=4, P<$ $0 \cdot 001$, for peat and $\chi^{2}=7052 \cdot 903$, D.F. $=4, P<0 \cdot 001$, for sand). While $S$. carpocapsae tended to dominate infections in the upper $5 \mathrm{~cm}$ in both habitats, and H. megidis dominated at $45 \mathrm{~cm}$ depth in both habitats, $S$. carpocapsae dominated the inner sections in peat, whereas in sand $H$. megidis dominated these sections (Fig. 4B).

\section{DISCUSSION}

Ambush and cruise foraging species have been described in numerous taxonomic groups of predators including birds, fish, mammals, reptiles, amphibians, insects, and arachnids (reviewed by Cooper, 2005). Whilst controversy exists about the utility of using ambush and cruise terminologies to describe foraging strategies of organisms (Cooper, 2005), it has been shown that certain habitat characteristics, particularly the physical structure of the habitat, can significantly affect patterns of animal locomotion, foraging behaviour and resource exploitation (Enders, 1975; Moermond, 1979; Robinson and Holmes, 1982; Johnson et al. 2008). The findings of the current study suggest that habitat quality (sand $v s$ peat) may also have important implications on the foraging behaviour of soil-transmitted parasites such as EPN.

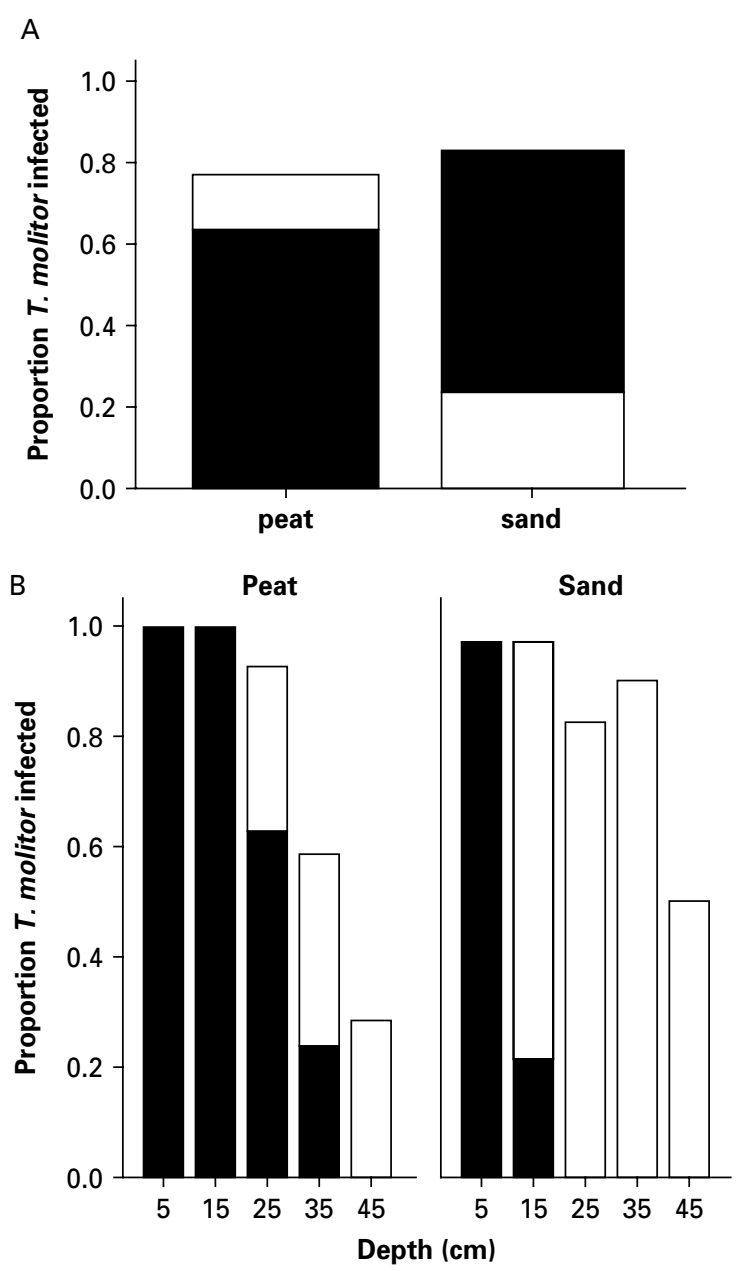

S. carpocapsae

H. megidis

Fig. 4. Mean proportion of Tenebrio molitor larvae infected by Steinernema carpocapsae or Heterorhabditis megidis when in competition with one another in (A) outdoor mesocosms containing sand or peat, (B) at varying depths within the mesocosms.

The vast majority of work on EPN behaviour and foraging strategy has been done using agar or sand (the latter being a good model for mineral soils with low organic matter). Our studies in sand produced results exactly as predicted by previous work: $H$. megidis (classified as a 'cruise' forager) showed high dispersal and strong taxis towards hosts, whereas S. carpocapsae (an 'ambusher') showed lower dispersal with no evidence of taxis towards hosts (Grewal et al. 1994).

In peat, our data were very different from those predicted by supposed foraging strategy. In this habitat it was $S$. carpocapsae that showed a significant taxis towards hosts whereas $H$. megidis did not. $S$. carpocapsae dispersal was greater in peat than sand, although in both habitats $H$. megidis dispersed more. The poor host finding capacity of $H$. megidis in peat may result from 'cruise' foragers' reliance on host volatiles (Lewis et al. 1993) which are thought to be adsorbed onto the organic matter in peat thus 
interfering with host finding (Torr et al. 2004). It may be that $S$. carpocapsae relies more on physical cues such as vibrations that will still be transmitted through peat (Torr et al., 2004). Other possible cues that could be used by $S$. carpocapsae in peat include temperature or certain inorganic molecules that would not bind to peat. Further research would be needed to confirm these hypotheses.

The superior host finding abilities of $H$. megidis in sand and $S$. carpocapsae in peat were confirmed in our mesocosm experiments. In the appropriate habitats, both nematodes could outcompete the other in terms of host finding and infection. In both habitats, $H$. megidis infected a greater percentage of the deepest-dwelling hosts. However, the greater dispersal of $H$. megidis over $S$. carpocapsae seen in our experiments may simply reflect the greater size of $H$. megidis IJs compared with those of $S$. carpocapsae (736-800 $\mu \mathrm{m}$ vs 438-650 $\mu \mathrm{m}$ respectively) (Nguyen, 2007).

We also documented that $H$. megidis can body wave on peat. It has been stated that this behaviour is an adaptation to ambush foraging where nematodes body wave at the soil surface in order to attach to passing insects (Campbell and Gaugler, 1993; Campbell and Kaya, 1999). However, other authors have suggested this to be a mechanism for bridging large pore spaces (Reed and Wallace, 1965) and thus could be of great use in moving in open structured organic environments (i.e. a high ratio of void space to matrix) such as peat, leaf litter or turfgrass thatch. Such large pores are unlikely to occur in sandy soils with low organic matter where many Heterorahbditis species tend to be found (Hara et al. 1991; Stock et al. 1999; Hominick et al. 2002). This may explain the lower tendency of certain Heterorhabditis spp. to body wave.

We believe that $H$. megidis, S. carpocapsae and possibly other EPN may be habitat specialists that exhibit behaviours that are adapted to life within a given niche. The very different behaviours of certain EPN species, e.g. H. megidis and S. carpocapsae, are usually explained in terms of foraging strategy and the cruise/ambush continuum. Our data provide an alternative hypothesis and suggest that $H$. megidis is adapted to life in sandy mineral soils and its distribution, along with many other heterorhabditids, e.g. H. marelatus confirms this (Hominick, 2002). We further believe that $S$. carpocapsae is adapted to life in organic material such as peat or leaf litter but little is known about the natural habitat of this species, or indeed many other steinernematids. In general, the presence of steinernematids tends to be highest in woodland (Hominick, 2002) but the position in the soil profile from which the nematodes are isolated is not generally recorded. However, the large layers of leaf litter present in forests, when compared with cultivated or grassland soils, would provide a suitable habitat for organic matter specialists.
Some support for our alternative hypothesis can be found in previous literature. Campbell et al. (1996) studied nematode prevalence in highly managed turfgrass - a man-made environment that could not have influenced the evolution of $S$. carpocapsae. In this environment, $S$. carpocapsae was common, but it was confined to the surface layers. Managed turfgrass contains a layer of thatch which is a tightly intermingled layer of living and dead root, stolons and undecomposed plant material - similar in many ways to the peat used in our experiments. These authors also commonly found Heterorhabditis bacteriophora but this species was largely confined to the mineral soil horizons.

Further support can be found in the studies of Lacey and Unruh (1998). They used entomopathogenic nematodes in field experiments to control cocooned larvae of Cydia pomonella on pear and apple logs and within leaf litter of these trees. In both these organic habitats they found that the 'ambusher' $S$. carpocapsae outperformed the 'cruiser' H. bacteriophora. Since the cocooned larvae are immobile, ambushing is not a plausible mode of host finding.

Yet more support for our hypothesis that certain EPN are habitat specialists can be found in the study of Powers et al. (2009). These authors showed that the EPN species found in the litter layer of a lowland tropical rainforest in Costa Rica were quite distinct from those found in the mineral horizons (Powers et al. 2009). Interestingly in the study of Powers et al. (2009), Heterorhabditis spp. were isolated from the litter and Steinernema spp. were isolated from the mineral soil. Further study of these isolates could prove valuable in understanding the behavioural ecology of EPN.

Our study clearly demonstrates that soil habitat quality influences foraging strategy, body-waving behaviour and competitive ability of these two species of soil-transmitted parasites. If EPN are habitat specialists, understanding such specializations will be crucial to harnessing their potential as bio-control agents. If our hypothesis is correct, it would be possible to use 'ambush' foraging nematodes to control deep-dwelling sedentary pests in peaty soil and there are published data to support this (Dillon et al. 2006; Torr et al. 2007 a).

\section{ACKNOWLEDGEMENTS}

We thank David Hay for the autoclaving of soils and Brian Stewart and Kevin Mackenzie for their help with the video (online version only) and the colour photograph in this paper. This work was funded by the Forestry Commission and The College of Life Science and Medicine of the University of Aberdeen.

\section{REFERENCES}

Campbell, J. F. and Gaugler, R. (1993). Nictation behaviour and its ecological implications in the host search strategies of entomopathogenic nematodes 
(Heterohabitidae and Steinernematidae). Behaviour 126, 155-169.

Campbell, J. F. and Kaya, H. K. (1999). How and why a parasitic nematode jumps. Nature, London 397, 485-486.

Campbell, J. F., Lewis, E., Yoder, F. and Gaugler, R. (1996). Entomopathogenic nematode (Heterorhabditidae and Steinernematidae) spatial distribution in turfgrass. Parasitology 113, 473-482.

Cooper, W. E. (2005). The foraging mode controversy: both continuous variation and clustering of foraging movements occur. Fournal of Zoology 267, 179-190.

Dillon, A. B., Rolston, A. N., Meade, C. V., Downes, M. J. and Griffin, C. T. (2008).

Establishment, persistence, and introgression of entomopathogenic nematodes in a forest ecosystem. Ecological Applications 18, 735-747.

Dillon, A. B., Ward, D., Downes, M. J. and Griffin, C. T. (2006). Suppression of the large pine weevil Hylobius abietis (Coleoptera: Curculionidae) in pine stumps by entomopathogenic nematodes with different foraging strategies. Biological Control 38, 217-226.

Emelianoff, V., Chapuis, E., Le Brun, N., Chiral, M., Moulia, C. and Ferdy, J-B. (2008). A survivalreproduction trade-off in entomopathogenic nematodes mediated by their bacterial symbionts. Evolution 62, 932-942.

Enders, F. (1975). The influence of hunting manner on prey size, particularly in spiders with long attack distances (Araneidae, Linyphiidae and Salticidae). American Naturalist 109, 737-763.

Grewal, P. S., Lewis, E. E., Gaugler, R. and Campbell, J. F. (1994). Host finding behaviour as a predictor of foraging strategy in entomopathogenic nematodes. Parasitology 108, 207-215.

Hara, A. H., Gaugler, R., Kaya, H. K. and Lebeck, L. M. (1991). Natural populations of entomopathogenic nematodes (Rhabditida: Heterorhabditidae, Steinernematidae) from the Hawaiian Islands. Environmental Entomology 20, 211-216.

Hominick, W. M. (2002). Biogeography. In Entomopathogenic Nematology (ed. Gaugler R.), pp. 115-144. CABI Publishing, Wallingford, UK.

Johnson, M. A., Leal, M., Schettino, L. R., Lara, A. C., Revell, L. J. and Losos, J. B. (2008). A phylogenetic perspective on foraging mode evolution and habitat use in West Indian Anolis lizards. Animal Behaviour 75, 555-563.

Kaya, H. K. and Gaugler, R. (1993). Entomopathogenic nematodes. Annual Review of Entomology 38, 181-206.

Kaya, H. K. and Stock, S. P. (1997). Techniques in insect nematology. In Manual of Techniques in Insect Pathology (ed. Lacey, L. A.), pp. 281-324. Academic Press, London, UK.

Kaya, H. K., Aguillera, M. M., Alumai, A., Choo, H. Y., Torre, M., Fodor, A., Ganguly, S., Hazir, S., Lakatos, T., Pye, A., Wilson, M., Yamanaka, S., Yang, H. and Ehlers, R.-U. (2006). Status of entomopathogenic nematodes and their symbiotic bacteria from selected countries or regions of the world. Biological Control 38, 134-155.

Klein, M. G. (1990). Efficacy against soil-inhabiting insect pests. In Entomopathogenic Nematodes in Biological
Control (ed. Gaugler, R. and Kaya, H. K.), pp. 195-214.

CRC Press, Boca Raton, FL, USA.

Lacey, L. A. and Unruh, T. R. (1998).

Entomopathogenic nematodes for control of codling moth, Cydia pomonella (Lepidoptera: Torticidae): effect of nematode species, concentration, temperature, and humidity. Biological Control 13, 190-197.

Lewis, E. E. (2002). Behavioural ecology. In Entomopathogenic Nematology (ed. Gaugler, R.), pp. 205-224. CABI Publishing, Wallingford, UK.

Lewis, E. E., Gaugler, R. and Harrison, R. (1992). Entomopathogenic nematode host finding: response to host cues by cruise and ambush foragers. Parasitology 105, 103-107.

Lewis, E. E., Gaugler, R. and Harrison, R. (1993). Response of cruiser and ambusher entomopathogenic nematodes (Steinernematidae) to host volatile cues. Canadian Fournal of Zoology 71, 765-769.

Moermond, T. C. (1979). The influence of habitat structure on Anolis foraging behaviour. Behaviour 70, 147-167.

Nguyen, K. B. (2007). Methodology, morphology and identification. In Entomopathogenic Nematodes: Systematics, Phylogeny and Bacterial Symbionts (ed. Nguyen, N. B. and Hunt, D. J.), pp. 59-119. Koninklijke Brill NV, The Netherlands.

Powers, T. O., Neher, D. A., Mullin, P., Esquivel, A., Giblin-Davis, R. M., Kanzaki, N., Stock, S. P., Mora, M. M. and Uribe-Lorio, L. (2009). Tropical nematode diversity: vertical stratification of nematode communities in a Costa Rican humid lowland rainforest. Molecular Ecology 18, 985-996.

Pyke, G. H., Pulliam, H. R. and Charnov, E. L. (1977). Optimal foraging: a selective review of theory and tests. The Quarterly Review of Biology 52, 137-154.

Ramos-Rodríguez, O., Campbell, J. F., Christen, J. M., Shapiro-Ilan, D. I., Lewis, E. E. and Ramaswamy, S. B. (2007). Attraction behaviour of three entomopathogenic nematode species towards infected and uninfected hosts. Parasitology 134, 729-738

Reed, E. M. and Wallace, H. R. (1965). Leaping locomotion by an insect-parasitic nematode. Nature, London 206, 210-211.

Robinson, S. K. and Holmes, R. T. (1982). Foraging behavior of forest birds: the relationship among search tactics, diet, and habitat structure. Ecology 63, 1918-1931.

San-Blas, E. and Gowen, S. R. (2008). Facultative scavenging as a survival strategy of entomopathogenic nematodes. International Fournal for Parasitology 38, 85-91.

Spiridonov, S. E., Reid, A. P., Podrucka, K., Subbotin, S. A. and Moens, M. (2004). Phylogenetic relationships within the genus Steinernema (Nematoda: Rhabditida) as inferred from analyses of sequences of the ITS1-5.8S-ITS2 region of rDNA and morphological features. Nematology $\mathbf{6}$, 547-566.

Stock, S. P., Pryor, B. M. and Kaya, H. K. (1999). Distribution of entomopathogenic nematodes (Steinernematidae and Heterorhabditidae) in natural habitats in California, USA. Biodiversity and Conservation 8, 535-549. 
Torr, P., Heritage, S. and Wilson, M. J. (2004).

Vibrations as a novel signal for host location by parasitic nematodes. International Fournal for Parasitology 34, 997-999.

Torr, P., Heritage, S. and Wilson, M. J. (2007a). Steinernema kraussei, an indigenous nematode found in coniferous woodlands: efficacy and field persistence against Hylobius abietis. Agricultural and Forest Entomology 9, 181-188.
Torr, P., Spiridonov, S. E., Heritage, S. and Wilson, M. J. (2007b). Habitat associations of two entomopathogenic nematodes: a quantitative study using real-time quantitative polymerase chain reactions. Fournal of Animal Ecology 76, 238-245.

Young, I. M. and Crawford, J. W. (2004). Interactions and self-organization in the soil-microbe complex. Science 304, 1634-1637. 